\title{
Analisis Cost Consequences Obat Kemoterapi pada Pasien Kanker Payudara di RS Pemerintah Kota Yogtakarta
}

\author{
Cost Consequences Analysis of Chemotherapy Drugs in Breast Cancer Patient in Regional Public Hospital \\ Yogyakarta
}

\author{
Hesty Riza Oktastika1, Woro Supadmi ${ }^{*}$, Endang Yuniarti ${ }^{2}$ \\ 1 Program Pascasarjana Fakultas Farmasi, Universitas Ahmad Dahlan \\ 2 Rumah Sakit PKU Muhammadyah Yogyakarta, STIKES Muhammadyah Gombong \\ Corresponding author: Woro Supadmi; Email: wsupadmi@yahoo.com \\ Submitted: 14-01-2021 Revised:24-02-2021 Accepted: 12-03-2021
}

\begin{abstract}
ABSTRAK
Kanker merupakan penyebab utama kematian didunia. Di Indonesia kanker payudara berada di urutan kedua. Prevalensi tertinggi kanker payudara di Indonesia tahun 2013 pada provinsi D.I. Yogyakarta yaitu sebesar 2,4\%. Pemberian kemoterapi menimbulkan efek samping berupa hiponatremi (20,2\%), neutropenia $(11,4 \%)$, leukopenia $(9,6 \%)$. Penatalaksanaan efek samping tersebut mempengaruhi biaya perawatan khususnya biaya medik. Penelitian ini menggunakan desain observasional. Pengambilan data secara retrospektif yaitu Januari 2018 - Desember 2019. Pemilihan subyek penelitian semua populasi pasien kanker payudara yang sesuai dengan kriteria inklusi. Perspekstif biaya berdasarkan perspektif provider meliputi biaya selama menjalani kemoterapi sampai selesai. Data yang diambil adalah kondisi pasien, keluhan dan penggunaan kemoterapi dan biaya dari bagian keuangan RS. Hasil penelitian menunjukkan regimen kemoterapi di RS Pemerintah Kota Yogyakarta pada periode 2018 - 2019 terdapat 6 variasi yang paling banyak digunakan adalah regimen TEC 41 pasien (54\%). Efek samping yang paling umum terjadi antara lain mual $(89,3 \%)$, muntah (88\%), neutropenia (60\%), leukopenia (54\%) dan anemia (46,7\%). Obat kemoterapi paling tinggi regimen BEC (Rp. 19.707,273) dan terendah TAC (Rp. 9.320,663). Biaya medik obat non kemoterapi tertinggi regimen BEC (Rp. 924,836) dan terendah regimen TE (Rp. 650,000). Biaya medik lain paling tinggi pada regimen BEC (Rp. 7.435,6943) dan paling rendah pada regimen TE (Rp. 6.752,639).
\end{abstract}

Kata kunci: Cost Consequences Analysis; kemoterapi; kanker payudara

\section{ABSTRACT}

Cancer is the leading cause of death in the world. In Indonesia, breast cancer is in second place. The highest prevalence of breast cancer in Indonesia in 2013 was in the province of D.I. Yogyakarta, namely $2.4 \%$. Giving chemotherapy caused side effects in the form of hyponatremia (20.2\%), neutropenia (11.4\%), and leukopenia (9.6\%). Management of these side effects affects the cost of treatment, especially medical costs. This study used an observational design. Retrospective data collection, January 2018 - December 2019. Selection of study subjects all breast cancer patient populations according to the inclusion criteria. The cost perspective based on the provider perspective includes costs during the course of chemotherapy to completion. The data taken is the patient's condition, complaints and the use of chemotherapy and costs from the hospital's financial department. The results showed the chemotherapy regimen at the Yogyakarta City Government Hospital in the period 2018 - 2019 there were 6 variations that were most widely used, namely the TEC regimen for 41 patients (54\%). The most common side effects included nausea (89.3\%), vomiting (88\%), neutropenia (60\%), leukopenia (54\%) and anemia (46.7\%). Chemotherapy drugs had the highest BEC regimen (Rp. 19,707,273) and the lowest was TAC (Rp. 9,320,663). The highest medical cost of non chemotherapy drugs was BEC regimen (Rp. 924,836) and the lowest was TE regimen (Rp. 650,000). Other medical costs were the highest in the BEC regimen (Rp. 7,435,6943) and the lowest in the TE regimen (Rp. 6,752,639).

Keywords: Cost Consequences Analysis; chemotherapy; breast cancer

\section{PENDAHULUAN}

Kanker merupakan salah satu penyakit utama penyebab kematian didunia. Pada 2012 diperkirakan terdapat 14 juta kasus baru kanker dan 8,2 juta kematian akibat kanker. WHO melaporkan lima besar jenis kanker didunia pada 2012 yaitu kanker paru, prostat, kolorektum, kanker perut dan kanker hati. Pada perempuan yang terbanyak adalah kanker payudara, kolorektum, paru-paru, serviks serta kanker perut. Survei World Health Organization (WHO) menyatakan 8-9\% wanita mengalami kanker payudara. Hal ini membuat kanker payudara sebagai jenis kanker yang paling banyak ditemui pada wanita. Data Global Burden of Disease (2013) menyatakan bahwa secara 
global terdapat 1,8 juta kasus kanker payudara dan 464.000 kasus menyebabkan kematian (Dewi, 2017).

Di Indonesia kanker payudara berada di urutan kedua setelah kanker serviks. Berdasarkan estimasi Globocan, International Agency for Research on Cancer (IARC) tahun 2012 diketahui bahwa kanker payudara merupakan penyakit kanker dengan persentase kasus baru tertinggi yaitu sebesar 43,3\% dan persentase kematian akibat kanker payudara sebesar 12,9\%. Prevalensi tertinggi kanker payudara di Indonesia tahun 2013 terdapat pada provinsi D.I. Yogyakarta yaitu sebesar 2,4\% dan berdasarkan estimasi jumlah kanker payudara terbanyak terdapat pada Provinsi Jawa Tengah yaitu 11.511 kasus (Nasution, Asfriyati and Siregar, 2018). Penatalaksanaan kanker payudara ini ada beberapa cara seperti operasi, terapi radiasi, terapi hormonal dan kemoterapi. Pengobatan yang paling sering dilakukan adalah kemoterapi (Sari, Indra and Lestari, 2019). Penatalaksanaan kanker tersebut memerlukan biaya yang cukup besar seperti penelitian yang dilakukan di RSUP dr. Wahidin Sudirohusodo, biaya rawat inap pembedahan memiliki rentang biaya yaitu Rp. 5.436.756 - Rp. 5.564.678 dengan komponen terbesar yaitu pada bahan medis habis pakai (BHP) yang termasuk biaya tindakan medik yaitu sebesar 28,6\%. Biaya rawat inap kemoterapi memiliki rentang biaya yaitu $\mathrm{Rp}$. 2.546.166 - Rp. 6.823.821 dengan komponen biaya terbesar pada rawat inap kemoterapi sebesar 83,5\%. Biaya rawat jalan memiliki rentang biaya yaitu Rp. 1.538 .750 - Rp. 4.202.935 dengan komponen biaya terbesar pada rawat jalan yaitu biaya obat sebesar 63,57\% (Musnelina, Pontoan and Martin, 2019). Efek samping yang ditimbulkan oleh pengobatan kemoterapi berupa fisik dan non fisik (psikologis), dari segi fisik dapat terjadi gangguan pada sumsum tulang belakang, gangguan saluran cerna (anoreksia), bersifat toksik pada organ lain (seperti jantung, hati, dan ginjal), rambut rontok hingga mengalami alopesia (Sari, Indra and Lestari, 2019). Efek samping yang paling sering dilaporkan antara lain hiponatremi $(20,2 \%)$, neutropenia $(11,4 \%)$, infeksi paru-paru $(11,4 \%)$, leukopenia $(9,6 \%)$. Obat yang dicurigai menimbulkan efek samping tersebut antara lain cisplatin (62,3\%), carboplatin $(18,4 \%)$, cetuximab $(3,5 \%)$ dan gefitinib (2,6\%). Efek samping yang terjadi $80 \%$ dicurigai dari obat-obat yang mengandung platinum (Bellare et al., 2016).

Terapi kanker payudara menggunakan kemoterapi dapat menimbulkan berbagai efek samping yang dapat mempengaruhi secara langsung kondisi klinis pasien dan biaya maka perlu dilakukan penelitian tentang Cost Consequens Analysis kemoterapi pada pasien kanker payudara. Analisis cost consequence (CCA) merupakan evaluasi ekonomi dimana biaya dan serangkaian hasilnya memungkinkan pembaca membentuk pendapat mereka sendiri, relevansi dan kepentingan relatif terhadap pengambilan keputusan mereka (Drummond et al, 2005). Analisis cost consequence dilakukan dengan menggunakan tabel deskriptif untuk menyajikan hasil efektivitas (hasil primer dan sekunder) dalam format terpisah engan perkiraan biaya rata-rata yang terkait dengan setiap intervensi (Drummond et al, 2005).

\section{METODOLOGI}

Penelitian ini adalah penelitian observasional deskriptif dengan pengambilan data secara retrospektif yaitu data bulan Januari 2018 - Desember 2019. Pemilihan subyek penelitian yaitu semua populasi pasien yang didiagnosa kanker payudara yang sesuai dengan kriteria inklusi. Perspekstif biaya yang digunakan berdasarkan perspektif provider (Rumah Sakit) yang berupa biaya medik langsung selama pasien menjalani kemoterapi sampai selesai. Penelitian ini telah mendapat persetujuan etik dari Komite Etik Penelitian Kesehatan RSUD Kota Yogyakarta dengan Nomor 36/KEP/RSUD/VIII/2020.

Populasi yang digunakan dalam penelitian ini adalah semua pasien dengan diagnosa kanker payudara yang menjalani kemoterapi pada periode 1 Januari 2018 - 31 Desember 2019 serta memiliki data yang lengkap meliputi nama, usia, berat badan, tinggi badan, diagnosa, nama obat yang didapatkan, dosis obat yang diberikan dan siklus obat kanker yang diperoleh. Data laboratorium dan biaya medik langsung sesuai dengan kriteria yang ditetapkan oleh peneliti.

Analisis data penelitian ini menggunakan analisis univariat dengan bantuan SPSS for Windows 7 versi 20.0. Analisis univariat dilakukan untuk mendeskripsikan setiap variabel yang diteliti meliputi dengan melihat semua distribusi data regimen, efek samping dan biaya. Analisis ini digunakan untuk 
Tabel I. Karakteristik Pasien Kanker Payudara RS Pemerintah Kota Yogyakarta Periode 2018 - 2019

\begin{tabular}{lcc}
\hline \multicolumn{1}{c}{ Karakteristik } & Jumlah & \% \\
\hline Umur & & 10,67 \\
$<40$ tahun & 8 & 89,33 \\
$>40$ tahun & 67 & \\
Regimen Terapi & & 40 \\
BEC & 30 & 54 \\
TEC & 41 & 1,3 \\
BE & 1 & 1,3 \\
TEV & 1 & 1,3 \\
BAC & 1 & 1,3 \\
TAC & 1 & 100 \\
Siklus & & 100 \\
VIII & 75 & 75 \\
Total & 75 & \\
\hline
\end{tabular}

Keterangan: TEC (Docetaxel, Epirubicin, Carboplatin); PEC (Paclitaxel, Epirubicin, Carboplatin); TE (Docetaxel, Epirubicin); PEV (Paclitaxel, Epirubisin, Vincristin); TAC (Docetaxel, Doxorubicin, Cisplatin); PAC (Paclitaxel, Dxorubicin, Cisplatin).

mendeskripsikan data seperti rerata, median, modus dan proporsi.

\section{HASIL DAN PEMBAHASAN \\ Karakteristik Pasien}

Data karakteristik pasien bertujuan untuk melihat gambaran pasien kanker payudara di RS Pemerintah Kota Yogyakarta periode 2018 - 2019. Data disajikan dalam bentuk deskriptif. Karakteristik dalam penelitian dapat dilihat pada tabel I.

Karakteristik pasien kanker payudara di RS Pemerintah Kota Yogyakarta periode 2018 - 2019 usia > 40 tahun terdapat lebih banyak yaitu 67 pasien $(89,33 \%)$ dibandingkan dengan usia $<40$ tahun terdapat 8 pasien $(10,67 \%)$. Sejalan dengan penelitian yang dilakukan oleh Desantis et al (2019) kejadian kanker payudara di Asia pada usia $>40$ tahun sebanyak (93\%) dan pada usia < 40\% sebanyak (7\%). Kejadian kanker payudara untuk semua ras sebanyak (96\%) terjadi pada usia > 40 tahun dan ssebanyak (4\%) terjadi pada usia $<40$ tahun. Berdasarkan American Cancer Society (2018) peningkatan resiko kanker payudara seiring dengan peningkatan usia disebabkan karena perubahan pola reproduksi, penggunaan hormon menopause dan meningkatnya prevalensi obesitas.

Penelitian ini menunjukkan regimen kemoterapi kanker payudara yang digunakan di RS Pemerintah Kota Yogyakarta adalah golongan taxan+antrasiklin+carboplatin. Regimen yang paling banyak digunakan adalah TEC (paclitaxel+epirubicin+carboplatin) sebanyak 39 pasien (52\%). Regimen terapi lain yang digunanakan adalah BEC (docetaxel+epirubicin+carboplatin) sebanyak 30 pasien $(40 \%)$, regimen BE (docetaxel+epirubicin) sebanyak 1 pasien $(1,3 \%)$, regimen TEV (paclitaxel+epirubicin+vincristin) sebanyak 1 pasien $(1,3 \%), \quad$ regimen BAC (docetaxel+doxorubicin+cisplatin) sebanyak 1 pasien $(1,3 \%)$ dan regimen TAC (paclitaxel+doxorubicin+cisplatin) sebanyak 1 pasien (1,3\%). Sejalan dengan penelitian Castrellon et al., (2018) yaitu kombinasi kemoterapi dengan regimen paclitaxel+antrasiklin+carboplatin memberikan respon patologis lengkap sebesar $(60 \%)$ pada pasien penderita ca mammae.

Berdasarkan tabel I menunjukkan jumlah siklus kemoterapi di RS Pemerintah Kota Yogyakarta periode 2018 - 2019 seluruh pasien sama yaitu 8 siklus dengan interval 21 hari.

\section{Efek Samping Kemoterapi}

Data efek samping obat kemoterapi disajikan dalam bentuk presentase dari masing - masing regimen kemoterapi. Efek samping pasien ca mammae yang menjalani kemoterapi di RS Pemerintah Kota Yogyakarta periode 2018 - 2019 dapat dilihat pada tabel II. 
Hesty Riza Oktastika, et al

Tabel II. Cost Consequences Analysis Obat Kemoterapsi Pasien Kanker Payudara di RS Pemerintah Kota Yogyakarta Periode Januari 2018 - Desember 2019

\begin{tabular}{|c|c|c|c|c|c|c|}
\hline \multirow[t]{2}{*}{ Biaya } & $\begin{array}{c}\text { BEC } \\
(n=30)\end{array}$ & $\begin{array}{c}\text { TEC } \\
(n=41)\end{array}$ & $\begin{array}{c}\text { TE } \\
(n=1)\end{array}$ & $\begin{array}{c}\text { TEV } \\
(n=1)\end{array}$ & $\begin{array}{c}\text { BAC } \\
(n=1)\end{array}$ & $\begin{array}{c}\text { TAC } \\
(n=1)\end{array}$ \\
\hline & \multicolumn{6}{|c|}{ Rata-rata biaya per pasien (rupiah) } \\
\hline Obat kemoterapi & $19.707,273$ & $5.797,572$ & $17.130,736$ & $13.932,03$ & $13.389,608$ & $9.320,663$ \\
\hline Obat efek samping & 924,836 & 802,861 & 650,747 & 649,641 & 718,289 & 802,379 \\
\hline Medik lainnya & $7.435,6943$ & $6.999,145$ & $6.752,639$ & $7.005,810$ & $6.744,540$ & $6.901,350$ \\
\hline Total & $28.067,803$ & $23.599,578$ & $24.534,122$ & $21.587,481$ & $20.852,437$ & $17.024,392$ \\
\hline Konsekuensi & \multicolumn{6}{|c|}{ Jumlah pasien $(n=75)$} \\
\hline CIPN & 2 & 5 & & & & \\
\hline Neutropenia & 17 & 26 & & 1 & 1 & \\
\hline Leukopenia & 17 & 22 & 1 & & 1 & \\
\hline Anemia & 19 & 14 & & 1 & 1 & \\
\hline Nausea & 26 & 39 & & 1 & & 1 \\
\hline Vomitting & 25 & 37 & 1 & 1 & 1 & 1 \\
\hline$\downarrow$ nafsu makan & 5 & 7 & & & & \\
\hline Diare & 9 & 4 & & & 1 & \\
\hline Konstipasi & 6 & 7 & & & & 1 \\
\hline Pusing & 6 & 8 & 1 & & & \\
\hline Sariawan & 7 & 9 & & & & 1 \\
\hline Infeksi kulit & 14 & 14 & & & & \\
\hline Insomnia & 5 & 5 & & & & \\
\hline Agranulositosis & & 4 & & & & \\
\hline
\end{tabular}

Keteran gan: BEC (Docetaxel, Epirubicin, Carboplatin); TEC ( Paclitaxel, Epirubicin, Carboplatin); TE (Docetaxel, Epirubicin); TEV (Paclitaxel, Epirubisin, Vincristin); BAC ( Docetaxel, Doxorubicin, Cisplatin); TAC ( Paclitaxel, Dxorubicin, Cisplatin).

Tabel II menunjukkan efek samping berupa CIPN (Chemotherapy Induced Pheripheral Neurophaty) sebanyak (9,3\%) yang terjadi pada pasien dengan regimen kemoterapi golongan taxan. CIPN disebabkan karena agen kemoterapi yang menyebabkan kerusakan pada struktur sistem syaraf. Prevalensi CIPN paling banyak disebabkan oleh regimen kemoterapi platinum-based $(70-100 \%)$ dan taxan sebanyak (11-87\%) (Zajaczkowską et al., 2019). Pasien yang mendapatkan paclitaxel (50\%) mengalami CIPN sedang atau lebih tinggi daripada pasien yang mendapatkan docetaxel $(17,7 \%)$ (Nyrop et al., 2019).

Efek samping berupa neutropenia pasca kemoterapi terjadi pada sebanyak 45 pasien (60\%). Hasil penelitian Zhou et al., (2017) menunjukkan bahwa terjadi efek samping berupa neutropenia akibat penggunaan regimen kemoterapi paclitaxel+platinum sebanyak 51 pasien $(38,9 \%)$ dari total 131 pasien. Park et al., (2019) juga membuktikan bahwa regimen kemoterapi adjuvan taxan+antrasiklin pada $c a$ mammae dapat menginduksi terjadinya efek samping berupa neutropenia. Total 102 pasien dalam penelitian tersebut mengalami efek samping berupa neutropenia sebanyak 64 pasien $(62,8 \%)$.

Efek samping berupa leukopenia pasca kemoterapi terjadi pada pasien sebanyak 41 pasien (54\%). Hasil penelitian yang dilakukan oleh Charles et al., (2016) di RS Sadikin Bandung menunjukkan dari 33 pasien yang menjalani kemoterapi dengan regimen paclitaxel+platinum mengalami efek samping berupa leukopenia sebesar (57,6\%). Zhou et al., (2017) juga membuktikan bahwa dari 131 pasien ca mammae yang menjalani kemoterapi menggunakan regimen paclitaxel+platinum mengalami efek samping leukopenia sebanyak 79 pasien $(60,3 \%)$.

Efek samping berupa anemia pasca kemoterapi terjadi pada pasien sebanyak (46,7\%). Penelitian Hussein et al., (2020) menunjukkan bahwa terjadi penurunan nilai hemoglobin yang signifikan $(<0,01)$ pada 
kelompok ca mammae ketika dibandingkan dengan kelompok kontrol. Penurunan hemoglobin pada kelompok ca mammae yang menjalani kemoterapi ini dapat menyebabkan anemia. Pourali et al., (2017) juga membuktikan bahwa dari total 144 pasien mengalami efek samping berupa anemia sebanyak $(43,1 \%)$. Prevalensi anemia tersebut lebih tinggi pada pasien yang menjalani banyak siklus kemoterapi yaitu $(38,2 \%)$ pada pasien yang menjalan 6 siklus kemoterapi dan (50,9\%) pada pasien yang menjalani 8 siklus kemoterapi. Hasil penelitian tersebut menunjukkan bahwa efek samping berupa anemia paling banyak terjadi pada pasien dengan regimen kemoterapi paclitaxel+antrasiklin yaitu sebanyak $(61,1 \%)$ dan regimen docetaxel+antrasiklin sebanyak $(52,2 \%)$.

Kejadian efek samping nausea/vomiting hampir diseluruh pasien dengan persentase nausea $(89,3 \%)$ dan vomiting (88\%). Penelitian (Naito et al., 2020) membuktikan dari 75 pasien yang menjalani kemoterapi mengalami efek samping berupa nausea $(44,6 \%)$ dan vomitting $(13,5 \%)$.

Efek samping berupa diare dan konstipasi akibat kemoterapi terjadi sebanyak $(18,6 \%)$ pada diare dan $(18,6 \%)$ pada konstipasi. Penggunaan agen kemoterapi dapat meningkatkan efek samping sitotoksik yang signifikan pada gastrointestinal (seperti diare dan konstipasi). Diare yang diinduksi oleh agen kemoterapi merupakan bentuk dari mucositis gastrointestinal dimana terjadi cedera mukosa yang muncul sebagai inflamasi dan ulserasi yang mengakibatkan perubahan mikroflora usus dan sekresi GI. Konstipasi juga merupakan efek samping gastrointestinal yang diakibatkan oleh pemberian agen kemoterapi. Agen kemoterapi seperti cisplatin dan alkaloid vinca (vincristine, vinblastine, vinorelbine) dapat menginduksi terjadinya konstipasi sebanyak (80 - 90\%) pasien. (McQuade et al., 2016).

Efek samping pasca kemoterapi berupa anoreksia sebanyak (16\%). Hal ini sejalan dengan penelitian Zaini et al. (2015) bahwa terjadi efek samping anoreksia pada pasien $c a$ mammae yang menjalani kemoterapi sebanyak 101 pasien (32,77\%). Penyebab utama anoreksia pada kanker diakibatkan adanya peningkatan sitokin proinflamasi. Faktor ini memodulasi sistem neurotransmitter kaskade. Neurotransmitter menghasilkan efek anorektik melalui koenzim A / sistem lemak di hipotalamus. Penyebab sekunder diakkibatkan karena kemoterapi (Ezeoke and Morley, 2015).

\section{Biaya}

Data biaya pada penelitian ini disajikan dalam bentuk deskriptif bertujuan untuk melihat gambaran biaya obat kemoterapi dan medik langsung lainnya pada pasien kanker payudara yang menjalani kemoterapi di RS Pemerintah Kota Yogyakarta periode 2018 2019. Biaya medik langsung yang diambil berupa biaya obat kemoterapi, biaya obat non kemoterapi dan biaya jasa, biaya pemeriksaan lab, biaya alat kesehatan dan medik lainnya (non obat) dapat dilihat pada tabel VIII.

Berdasarkan tabel VIII. biaya obat kemoterapi paling tinggi regimen BEC (Rp. $19.707,273)$ dan terendah TAC (Rp. 9.320,663). Biaya medik obat non kemoterapi tertinggi pada regimen BEC (Rp. 924,836) dan terendah pada regimen TE (Rp. 650,000). Biaya medik lain paling tinggi pada regimen BEC (Rp. 7.435,6943) dan paling rendah pada regimen TE (Rp. 6.752,639). Hal ini sejalan dengan penelitian yang dilakukan oleh Musnelina, Pontoan and Martin, (2019) di RSPAD Gatot Subroto Jakarta bahwa biaya obat kemoterapi kanker payudara dengan regimen doxorubicin-paclitaxel sebesar 1,8 juta per pasien. Biaya obat non kemoterapi sebesar 0,8 juta per pasien.

\section{KESIMPULAN}

Regimen kemoterapi yang digunakan di RS Pemerintah Kota Yogyakarta pada periode 2018 - 2019 terdapat 6 variasi yang paling banyak digunakan adalah regimen TEC 41 pasien (54\%). Efek samping yang paling umum terjadi pada pasien pasca kemoterapi antara lain mual (89,3\%), muntah (88\%), neutropenia (60\%), leukopenia (54\%) dan anemia $(46,7 \%)$. Obat kemoterapi paling tinggi regimen BEC (Rp. 19.707,273) dan terendah TAC (Rp. 9.320,663). Biaya medik obat non kemoterapi tertinggi pada regimen BEC (Rp. 924,836) dan terendah pada regimen TE (Rp. $650,000)$. Biaya medik lain paling tinggi pada regimen BEC (Rp. 7.435,6943) dan paling rendah pada regimen TE (Rp. 6.752,639).

\section{UCAPAN TERIMAKASIH}

Penulis mengucapkan terima kasih kepada Direktur RSUD Kota Yogyakarta yang telah memberikan izin kepada peneliti untuk 
Hesty Riza Oktastika, et al

melakukan penelitian. Penulis juga mengucapkan terima kasih kepada pembimbing yang telah memberikan bimbingan dalam menyelesaikan penelitian ini.

\section{DAFTAR PUSTAKA}

Bellare, P. S. et al. (2016) 'A Retrospective Evaluation of Adverse Drug Reactions Due to Cancer Chemotherapy in a Tertiary Care Hospital in South India', 8(3), pp. 251-254.

Charles, A. et al. (2016) 'Paclitaxel-Carboplatin Chemotherapy Induced Hematologic Toxicities Among Epithelial Ovarian Cancer Patients', Universa Medicina, 35(3), p. 165.

Dewi, M. (2017) 'Sebaran Kanker di Indonesia, Riset Kesehatan Dasar 2007', Indonesian Journal of Cancer, 11(1), pp. 1-8.

Dinas Kesehatan DIY (2019) 'Profil Kesehatan D.I Yogyakarta tahun 2018', Profil Kesehatan Daerah Istimewa Yogyakarta tahun 2018, p. 32. Available at: http://www.dinkes.jogjaprov.go.id/dow nload/download/27.

Ezeoke, C. C. and Morley, J. E. (2015) 'Pathophysiology of Anorexia in the Cancer Cachexia Syndrome', Journal of Cachexia, Sarcopenia and Muscle, 6(4), pp. 287-302.

McQuade, R. M. et al. (2016) 'ChemotherapyInduced Constipation and Diarrhea: Pathophysiology, Current and Emerging Treatments', Frontiers in Pharmacology, 7(NOV), pp. 1-14.

Naito, Y. et al. (2020) 'Chemotherapy-Induced Nausea and Vomiting in Patients With Breast Cancer: a Prospective Cohort Study', Breast Cancer. Springer Japan,

Nasution, W. M., Asfriyati and Siregar, F. A. (2018) 'Pengaruh Pemakaian Kontrasepsi Hormonal Dan Riwayat
Keluarga Terhadap Kejadian Kanker Payudara di RSUD Dr. PIirngadi Medan Tahun 2017', Jurnal Medika Respati, 13(April).

Nyrop, K. A. et al. (2019) 'Patient-Reported and Clinician-Reported ChemotherapyInduced Peripheral Neuropathy in Patients With Early Breast Cancer: Current Clinical Practice', Cancer, 125(17), pp. 2945-2954.

Musnelina, L., Pontoan, J. and Martin, C. J. (2019) 'Analisis Efektivitas Biaya Kemoterapi Pada Pasien Kanker Payudara Di RSPAD Gatot Soebroto Jakarta', 5(1), pp. 65-72.

Park, B. K. et al. (2019) 'Incidence of Febrile Neutropenia in Advanced Breast Cancer Patients Receiving Adjuvant DocetaxelDoxorubicin - Cyclophosphamide Chemotherapy in Korea and Its Impact on Prognosis', Journal of Breast Disease, 7(2), pp. 97-104.

Pourali, L. et al. (2017) 'Frequency of Chemotherapy Induced Anemia in Breast Cancer Patients', International Journal of Cancer Management, 10(1), pp. 1-6.

Sari, S. L., Indra, R. L. and Lestari, R. F. (2019) 'Korelasi Persepsi Tentang Efek Samping Kemoterapi Dengan Kualitas Hidup Pasien Kanker Payudara Shanti Lesmana Sari, Rani Lisa Indra, Raja Fitriana Lestari', Jurnal Cakrawala Promkes, 1(2), pp. 40-47.

Zajaczkowska, R. et al. (2019) 'Mechanisms of Chemotherapy-Induced Peripheral Neuropathy', International Journal of Molecular Sciences, 20(6).

Zhou, L. et al. (2017) 'Weekly Paclitaxel and Cisplatin as Neoadjuvant Chemotherapy with Locally Advanced Breast Cancer: A Prospective, Single Arm, Phase II Study', Oncotarget, 8(45), pp. 79305-79314. 